RTIGOS 


\title{
"This is America": uma reflexão sobre a potência do audiovisual para a construção do indizível
}

\author{
"This is America": a reflection about the power of the \\ audiovisual for the construction of the unspeakable
}

\section{Sophia Prado}

Brasil. Universidade Federal Fluminense. Doutoranda em Antropologia pela Universidade Federal Fluminense (UFF). Mestra em Antropologia Social pela Universidade Federal do Rio Grande do Norte (UFRN, 2016). Especialista em Teoria Geral do Crime pela Universidade de Coimbra e pelo Instituto Brasileiro de Ciências Criminais (IBCCRIM, 2014). Graduada em Direito (UFRN, 2013). ID ORCID: https://orcid.org/0000-0002-4708-6847.E-mail: sophialucprado@gmail.com.

\section{Resumo}

"This is America" foi considerado o clipe com a melhor estreia no YouTube em 2018. Em sua obra, Childish Gambino traz como reflexão imediata uma discussão sobre a tensão racial nos Estados Unidos e suas consequências na vida da população negra norte-americana. Entretanto, partindo do pressuposto de que, quando se trata de interpretar a arte, a mensagem só se conclui com a intervenção daquele que a lê, neste trabalho reflito sobre a forma como ele me tocou diante da minha vivência como antropóloga e produtora cultural nordestina trabalhando na periferia do Rio de Janeiro. Assim, utilizo o clipe como matéria-prima para refletir sobre a engrenagem de gestão governamental das mortes da população negra e favelada no Rio de Janeiro, acionando autores para discutir conceitos como necropolítica, homo sacer, vida precária e captura, todos muito presentes no discurso imagético proposto por Gambino. Nesse caminho, é possível perceber a potência do audiovisual quando a mensagem não se traduz em palavras, mas em sensações. Nesses casos, ela abandona a intenção do autor e se multiplica em infinitas possibilidades.

Palavras-chave: Audiovisual, Necropolítica, Subjetividade, Sensibilização.

Recebido em 24 de setembro de 2018

Avaliador A: 29 de novembro de 2018

Avaliador B: 09 de junho de 2019 Aceito em 09 de junho de 2019 


\section{Abstract}

"This is America" was considered the clip with the best debut on YouTube in 2018. In his work, Gambino discusses the racial tension in the United States and its consequences on the life of the American black population. However, based on the assumption that when it comes to interpreting art, the message conveyed is only concluded with the intervention of the person reading it, in this paper, I reflect on how he moved me with regard to my experience as an anthropologist and cultural producer of the northeast of Brazil, working in the outskirts of Rio de Janeiro. Thus, the clip serves as raw material to reflect on the machinery that is governmental management concerning the deaths of the black population living in the favelas of Rio de Janeiro, mentioning specific authors to discuss concepts such as necropolitics, homo sacer, precarious life and capture, which can be seen in the imagetic discourse proposed by Gambino. Such analysis allows to perceive the power of audiovisual media when the message does not translate into words, but into sensations. In such cases, it abandons the author's intent and multiplies itself into infinite possibilities.

Keywords: Audiovisual, Necropolitics, Subjectivity, Awareness.

\section{ONDE AS HISTÓRIAS SE CRUZAM}

Costumo dizer que há pesquisas que escolhemos, já outras não nos dão esse privilégio. Falar sobre necropolítica foi uma escolha que não fiz. Apenas o tema me invadiu de forma tal que não houve como fugir dele. Creio que minhas pesquisas têm seguido essa tendência de forma geral, mas não cabe aqui traçar maiores considerações sobre isso. Basta que se entenda que vim para o Rio de Janeiro com intenção a de dar continuidade à pesquisa que iniciei no mestrado e falar sobre roubo, sobre performance no crime, mas a vida sempre nos surpreende e nos retira da nossa zona de conforto. Às vezes de forma branda, outras nem tanto.

$\mathrm{Na}$ minha ânsia por fugir um pouco das teorias acadêmicas, comecei a trabalhar como produtora cultural independente, mas, para mim, isso só faria sentido se fosse na periferia. Não sem muita dor e jogo de cintura, consegui espaço em alguns territórios. Na verdade, sigo lutando por eles, tentando 
mostrar que, mesmo que a eles não pertença, por tanto me sensibilizar com essa luta, posso ter condições de contribuir com ela de alguma maneira.

Todos os meus companheiros de trabalho pertencem a essas localidades, por isso sempre fui considerada a "cota zona sul", como diziam. Obviamente, não pretendo, aqui, iniciar uma lamentação sobre os problemas que enfrentei em função disso, embora eles tenham sido inúmeros e de diferentes naturezas. O fato é que, a partir de algum momento, foram inseridos no meu cotidiano alguns elementos com os quais eu não estava habituada a lidar, quais sejam: favela, periferia, movimento negro e morte.

Não é possível, hoje, trabalhar com cultura na periferia do Rio de Janeiro sem refletir sobre lugar de fala. Essa questão que permeia as discussões antropológicas há tanto tempo, atualmente, se encontra em qualquer discurso sobre minorias, independentemente do seu contexto. Ainda bem! Apesar de não me dedicar a aprofundar essa questão neste ensaio, não creio que seja um ponto que possa passar despercebido em qualquer reflexão construída a partir de uma vivência em espaços como os que eu trabalhei. Especialmente no meu caso, já que meu estranhamento em relação a essa nova realidade que me era apresentada foi o ponto de partida para a discussão que pretendo travar.

Obviamente, há favelas em Natal, cidade onde nasci e cresci. Sem dúvida, não é possível compará-las às favelas cariocas, sobretudo ao Complexo da Maré e ao Complexo do Alemão, que foram os territórios onde tive a oportunidade de dialogar com mais proximidade. $\mathrm{O}$ que estou procurando demonstrar é que as favelas de Natal, por milhares de fatores que não me dedicarei aqui a explorar, não estão tão presentes no imaginário coletivo da cidade, mas, especialmente, eu não estava nelas. Elas não faziam parte do meu conjunto de reflexões diárias como fazem hoje.

O Rio Grande do Norte teve uma intensa imigração holandesa, francesa e americana, além da portuguesa. Por ter sido uma vila pouco robusta na época colonial, teve um tráfico negreiro incipiente em relação a outras capitais nordestinas. Como consequência disso, a população preta da capital potiguar, segundo dados do Instituto Brasileiro de Geografia e Estatística de 2010, representa apenas 4,68\% da população total. Com esse breve devaneio, pretendo chegar ao seguinte ponto: sem dúvida, o movimento negro natalense não apenas é 
muito mais embrionário que o do Rio de Janeiro como a própria leitura que eu fazia de mim, como uma pessoa não branca, passou a fazer parte dos meus questionamentos diários ao chegar na capital carioca. Aqui, sem dúvida, eu não poderia ser considerada uma pessoa preta, embora tivesse, na minha cidade e, mais ainda, nos brancos círculos de pessoas que eu frequentava, passado por inúmeras situações de racismo. Poderia não ser preta, mas ser considerada branca foi algo que jamais havia se passado pela minha cabeça.

O fato é que tudo isso subitamente invadiu minha vida, e eu, da maneira que pude, tentei abraçar cada oportunidade de aprendizado e escuta. Com o trabalho do tempo, cada questionamento foi sendo pouco a pouco digerido e assim fui tentando seguir desde então. A morte, porém, não digeri. Engasgo cada vez que deparo até mesmo com a lembrança dela e, talvez por isso, falar sobre o roubo já não fazia sentido para mim. Para essa nova pessoa que nascia, pensá-lo me parecia tão fútil quanto falar sobre meus problemas aqui. Entretanto, considerando a importância de refletir sobre o lugar de fala, senti-me na obrigação de narrá-los, mesmo encarando-os dessa forma. A morte que aterrorizava meus amigos e, por conseguinte, a mim era uma sombra cotidiana que eu não conhecia e que hoje já não sou capaz de esquecer. Ela estava na reunião desmarcada por uma ação militar na favela; no medo de sair do trabalho sozinha, às vezes, tarde da noite, sem estar com um amigo da região; no evento em que quase nenhum amigo da zona sul comparecia pelo receio de frequentar "certos locais" de madrugada; na lembrança do conhecido morto; na revolta pela vereadora executada; e em tantas outras regiões da minha memória, até hoje, difíceis de visitar. A morte estava em todo lugar. Ela está. E é desse lugar que eu saio para olhar para o clipe de Childish Gambino.

\section{ALGUMAS LEITURAS POSSÍVEIS}

Com apenas 24 horas no ar, "This is America" alcançou a marca de 12,9 milhões de visualizações no YouTube e logo se transformou em motivo de debate

\footnotetext{
Disponível em: http://bit.ly/2R8ngMX. Acesso em: 10 jul. 2018.
} 
nas redes sociais. O vídeo, lançado em maio de 2018, foi, também, o que chegou a 100 milhões de visualizações mais rapidamente na história da plataforma e, hoje, já superou a marca de 330 milhões. O clipe de Childish Gambino - nome artístico no mundo da música do ator, roteirista e produtor Donald Glover - foi dirigido por Hiro Murai e gerou uma comoção mundial, suscitando as mais diversas interpretações. O clipe, coreografado pela ruandense Sherrie Silver, também foi vencedor da categoria "Melhor Luta Contra o Sistema" do MTV Video Music Awards (VMA), uma das maiores premiações da música americana.

A crítica sarcástica proposta pelo clipe reflete sobre algumas das inúmeras contradições da sociedade norte americana, mas especialmente sobre a adoração às armas e à passividade em relação à banalização da violência contra a população negra. A farsa do American dream, que instituiu a imagem dos Estados Unidos como espaço de liberdade e igualdade de oportunidades, já não é novidade, mas, em sua sátira, o autor escancara essa hipocrisia por meio de uma linguagem inovadora e controversa.

Assim que lançado, o clipe suscitou as mais variadas interpretações do público e especialistas (ALONSO, 2018; JUNIOR, 2018; MARTÍNEZ, 2018; TERTO, 2018). Algumas leituras, por serem mais evidentes, por terem partido de estudiosos ou simplesmente por terem sido reproduzidas vezes suficientes para adquirirem um "status de verdade", foram incorporadas à maior parte das análises feitas. Para elaborar este ensaio, procurei ler críticas, textos e comentários em mídias sociais de pessoas que, como eu, tinham sido afetadas pelo clipe e procuravam entender um pouco melhor a proposta de Glover. Que sensações me eram despertadas e como elas dialogavam com as interpretações formuladas? Tomei essa pergunta como guia e agora trago, aqui, algumas dessas referências enquanto faço minha própria leitura.

Parto da hipótese de Didi-Huberman (2012) de que "as imagens ardem em seu contato com o real", se inflamam e nos consomem. Diz o autor que, pela aproximação, pelo desejo que a anima, pela destruição, pelo resplendor, por seu intempestivo movimento e audácia, pela dor e pela memória, a imagem arde a fim de, por sua própria via, instigar uma resposta, um convite para o discernimento ou a ação. Saber olhar uma imagem seria, então, “tornar-se capaz de 
discernir o lugar onde arde, o lugar onde sua eventual beleza reserva um espaço a um 'sinal secreto', uma crise não apaziguada, um sintoma. O lugar onde a cinza não esfriou" (DIDI-HUBERMAN, 2012, p. 215). No silêncio que gera, a imagem impõe "um trabalho de linguagem capaz de operar uma crítica de seus próprios clichês. Uma imagem bem olhada seria, portanto, uma imagem que soube desconcertar, depois renovar nossa linguagem, e portanto nosso pensamento" (DIDI-HUBERMAN, 2012, p. 216).

Disso se aduz que a legibilidade da imagem não está dada de antemão, não tem um caráter específico e fechado, mas é uma "encruzilhada dos caminhos". Ela gera desconcerto justamente pela incapacidade imediata que provoca de dar sentido, inclusive para descrever. Por isso, para seguir o caminho proposto pelo autor, "é preciso acercar o rosto à cinza. E soprar suavemente para que a brasa, sob as cinzas, volte a emitir seu calor, seu resplendor, seu perigo" (DIDI-HUBERMAN, 2012, p. 216). Procuro, portanto, interrogar essas imagens de Glover, refletir sobre o conhecimento a que dão lugar, sobre suas contribuições, olhando-as "a partir de sua função vital: urgente, ardente, tanto como paciente" (DIDI-HUBERMAN, 2012, p. 214, grifo do autor). Em contato com o real, como ilumina Didi-Huberman (2019), a imagem produz incêndio. O que trouxe aqui, foram partes do meu incêndio.

O clipe se inicia com a imagem de um violão sobre uma cadeira, em um galpão aparentemente vazio. Um homem negro entra em cena e começa a tocar o violão. Nesse momento, percebemos Gambino ao fundo, de costas e inerte. Pouco a pouco ele começa a se mover ao ritmo da música e, já em primeiro plano, vira de frente para a câmera, mas sem encará-la diretamente. Ele olha para o chão enquanto reproduz movimentos que intercalam certa suavidade e sensualidade - posto que focados basicamente na movimentação dos quadris acompanhados de uma expressão um pouco perdida, talvez de sofrimento - com uma dança mais dura e uma face rígida, que parece querer ressaltar mais seus músculos e assim remeter à força, à agressividade, à masculinidade. Nesse momento, a leitura mais clara que consigo fazer se relaciona à sexualização do homem negro ${ }^{2}$, a qual também o aprisiona de alguma maneira.

Para aprofundar o tema, cf. Davis (2016). 
Umas das expressões mais características do autor, nesse momento, se dá quando ele arregala o olho direito e fecha o esquerdo, o que, para alguns, seria uma referência ao Tio Ruckus. O personagem de ficção, um homem negro que acredita ser branco e que mostra tendências racistas, é o antagonista da história em quadrinhos The Boondocks ${ }^{3}$.

O cantor está usando uma calça que, segundo especialistas, é idêntica à do uniforme oficial dos Confederados, soldados que lutaram na guerra civil americana e que eram contra a libertação dos escravos, que foi considerada o estopim do conflito.

O clipe segue em plano-sequência, e Gambino, fazendo uma posição peculiar, tira uma arma do bolso e atira na cabeça do homem que tocava, agora encapuzado e já sem violão. A postura do cantor foi associada a Jim Crow, personagem de um espetáculo blackface criado por Thomas D. Rice no século XIX. Ele reproduzia todos os estereótipos negativos relacionados à comunidade negra e ficou tão popular que chegou a dar nome a um conjunto de leis que promoveram a segregação racial nos Estados Unidos até 1965.

A morte do homem deu brechas a muitas interpretações, mas, considerando a crítica que o autor faz em sua série Atlanta, acredito que ele pudesse realmente estar questionando os rumos da música negra nos Estados Unidos, tendo em vista que, atualmente, grande parte dela está voltada à valorização da cultura do consumo.

Depois de atirar, Glover olha diretamente para a câmera pela primeira vez e fala: "This is America". Ele entrega a arma a um adolescente, que a pega cuidadosamente, e dois outros arrastam o corpo do homem morto para fora da cena, deixando um rastro de sangue. Nesse momento, fica clara a crítica que faz a esse país, onde as armas são mais valorizadas do que a vida do homem negro que ela tira.

\footnotetext{
The Boondocks foi uma tirinha diária escrita e originalmente desenhada por Aaron McGruder em 1996 (p.5) para o The Diamondback, um jornal estudantil da Universidade de Maryland. No ano seguinte, foi impressa na revista mensal de hip-hop The Source e em 1999 foi adquirida pela Universal Press Syndicate. A tirinha fala sobre a cultura afro-americana e a política estadunidense a partir da perspectiva de um menino de dez anos, Huey Freeman, mas já esteve envolvida em várias polêmicas e foi acusada de racismo. The Boondocks foi comprada pela Sony Pictures Entertainment e, em 2005, estreou como desenho animado no canal Cartoon Network.
} 
O autor vem caminhando e dançando em direção à câmera enquanto ela se afasta, mantendo o plano americano. Nesse momento, ele reproduz movimentos e expressões que se intercalam: ora sorri e dança de forma divertida e despreocupada, ora simula uma pessoa que parece estar sob efeito de drogas, fissurada, com os olhos arregalados e o tronco solto, cambaleante, sem muito controle de si. Enquanto isso, no fundo da cena, pessoas começam a correr e a subir em carros, deixando o cenário cada vez mais caótico. Creio que, aí, ele se refira às fugas que muitas vezes as pessoas acabam buscando para não encarar a realidade, preferindo dar as costas a ela.

Ainda em plano-sequência, alguns estudantes negros entram em cena e começam a dançar junto com ele. Ele está em destaque, em primeiro plano, fala "This is America" e olha para os jovens, claramente imitando-os, o que fez que alguns entendessem a cena como uma crítica à apropriação cultural que se faz da cultura negra. Nesse momento, todos dançam Gwara Gwara, uma dança sul-africana que ficou conhecida no mundo pop depois de uma apresentação da cantora Rihanna.

Considerando a letra da música, que nesse instante se refere à naturalização das armas nos Estados Unidos, também é possível entender a cena como uma crítica a esse comportamento, que muitas vezes as pessoas reproduzem sem necessariamente refletirem sobre ele. Você se sente obrigado a "seguir o baile"4.

Alguns entenderam que, em função das roupas utilizadas pelos jovens, havia uma referência ao Levante de Soweto, ocorrido em 1976 na África do Sul, quando estudantes negros protestaram por um sistema de educação igualitário para negros e brancos.

O fato desses jovens sempre aparecerem dançando alegres e despreocupados em meio ao caos também gerou muita controvérsia. Acredito que faz sentido entendê-lo como uma provocação que segue diferentes direções. Inicialmente, creio que há uma crítica à alienação vivida pela sociedade atual, que se acentua diante da superficialidade da cultura de massa. Em primeiro

\footnotetext{
Aqui é possível, também, refletir sobre o aspecto sensual do crime, como revela Katz (1988). A arma seduz, ela traz a sensação de poder e por isso se transforma, muito facilmente, em um objeto de desejo e autoafirmação.
} 
plano, eles distraem e dificultam a concentração do espectador em relação a tudo mais que acontece na cena. Também falou-se sobre a relação do negro com a indústria de entretenimento (branca), à qual a maior parte deles precisa recorrer para ascender socialmente.

Na cena seguinte aparece um coral gospel formado também por pessoas negras, que cantam alegremente. Gambino abre uma porta e entra em cena dançando e sorrindo no mesmo ritmo. De repente, o sorriso se fecha, ele pega uma metralhadora que lhe é jogada por alguém do lado de fora da cena e dispara contra o coral. Ali, o negro não tem direito à alegria. Pela primeira vez na cena, ele olha diretamente para câmera e fala "This is America". Novamente, um jovem recolhe a arma envolvendo-o em um lenço vermelho e Gambino deixa a cena pulando de alegria. Nesse caso, houve certo consenso e as pessoas acreditaram que o autor tentava traçar um paralelo em relação a um episódio ocorrido em 2015, quando um jovem branco matou nove pessoas em Charleston, uma das mais antigas e engajadas igrejas afro-americanas do país.

Ele segue caminhando, passa por um carro de polícia vazio e a câmera o segue, agora de perfil. Quando se trata de executar a população negra, a polícia nunca se faz presente. Várias pessoas correm na direção contrária à dele, que parece estar nadando contra a corrente. Na cena seguinte, ele aparece de costas para a câmera, que gira em torno dele, até que ele a encara diretamente e faz um gesto que muitos associaram a Richard Pryor ${ }^{5}$, comediante que tratou de temas relacionados ao racismo e à violência nos Estados Unidos por décadas.

Em certo momento, ele canta com atitude entusiasta: "Eu sou tão bonito! Eu uso Gucci! Veja como eu danço!”, enquanto no fundo do pavilhão industrial irrompe o horror. Alguém se suicida, um carro de polícia é vandalizado e, enquanto isso, vários jovens estão inertes, mexendo em seus celulares. Atrás deles, uma luz vermelha indica que há um fogo ali que, em breve, poderá queimá-los. Mas eles estão tão envolvidos em seus universos virtuais que parecem não perceber o que acontece ao seu redor. Aqui, a referência à alienação é outra vez evidente. Enquanto isso, na letra da música, Gambino diz: “This is a celly, that's a tool". Isto é, o celular é uma ferramenta e poderia ser utilizado de forma mais inteligente.

O americano também era cantor e escritor. 
Há um carro em chamas, outra vez, uma viatura abandonada e um homem, com um capuz preto, montado em um cavalo branco, que muitos entenderam como uma representação de um dos quatro cavaleiros do apocalipse. Apesar da alegria e do entretenimento que se passa no primeiro plano, se olharmos além, perceberemos que nem tudo está tão bem assim, mas muito pelo contrário.

Gambino faz um gesto como se estivesse atirando e, de repente, o galpão está vazio. Ele está aparente tranquilo, acende um cigarro que parece ser de maconha e sai do quadro. Há um travelling pelo chão cinza, onde muitos outros cigarros aparecem. Não era apenas ele, muitos outros pareciam fumar também, embora nada disso estivesse em evidência. As pessoas estão fazendo uso dessa substância, não se pode negar. É uma hipocrisia.

A câmera segue, o homem do violão que foi assassinado no início do clipe agora está vivo e tocando novamente. Gambino sobe em cima de um carro. Ele é o maioral, ele é James Brown. Ele reproduz os passos do rei do funk, mas o galpão está vazio. Não há ninguém para ver. A câmera vai se distanciando e, em seguida, aparece Gambino correndo, desesperado, sozinho, fugindo de um grupo de pessoas brancas. Eles só aparecem nesse momento do clipe, para persegui-lo. As vítimas, por sua vez, são sempre negras.

O clipe, de alguma maneira, reproduz a lógica da divulgação do horror, da beleza, do consumo e da morte. Nesse sentido, ele não traz nada novo, é o que todos estamos habituados a ver. Por outro lado, trata-se de uma denúncia, uma crítica irônica à forma como tudo isso é recebido e naturalizado pela população.

Mais do que um discurso isolado, o clipe compõe um movimento mundial antirracista que cresce em todo o mundo e se manifesta nas mais diferentes linguagens artísticas. 13 th $^{6}$, Atlanta $^{7}$, Cara gente branca (Dear White People) ${ }^{8}$,

\footnotetext{
O premiado documentário é dirigido por Ava DuVernay e fala sobre o sistema carcerário e étnico nos Estados Unidos.

7 A premiada série de televisão foi criada e estrelada por Donald Glover e trata das dificuldades do que é ser um jovem negro tentando sobreviver nos Estados Unidos.

8 A polêmica e aclamada série de televisão trata de forma satírica o racismo sofrido por jovens negros em universidades norte-americanas.
} 
Pantera Negra (Black Panther) ${ }^{9}$, Corra! (Get out) ${ }^{10}$, Olhos que condenam (When they see us) $)^{11}$, Infiltrado na Klan (BlacKkKlansman ${ }^{12}$, entre outros, são exemplos de criações audiovisuais recentes que representam esse movimento de ruptura com a lógica racista da indústria cinematográfica norte-americana. Essa busca para alcançar um ponto de inflexão também restou evidente no aclamado discurso de Oprah Winfrey no Golden Globes Awards de 2018 ${ }^{13}$. Com isso, o que se quer demonstrar é que essa voz e esse corpo, frequentemente marginalizados e, quando reconhecidos, recorrentemente marcados por estratégias de embranquecimento, estão cada vez mais ocupando espaços de poder e reivindicando uma lógica de valorização da cultura negra. Nesse sentido, o discurso não é em si uma novidade, mas, certamente, a visibilidade que lhe é dada.

Isso revela que, cada vez mais, as pessoas estão buscando uma arte crítica e que as represente. Ao elaborar um clipe cheio de referências e simbologias, Glover nos leva a fazer um exercício cuja ausência ele critica e nos obriga a sair da superficialidade para enxergar aquilo que, à primeira vista, não se pode ver. Para entendê-lo, é preciso ter uma percepção aguçada, questionar, olhar duas vezes. Sua crítica está para além da tela.

Creio que haja um movimento mundial nesse sentido na indústria musical. Cantoras pop como Katy Perry ${ }^{14} \mathrm{e}^{\text {Anitta }}{ }^{15}$, por exemplo, agora parecem estar engajadas em discutir temas mais profundos do que os de costume, mas nem

\footnotetext{
A ficção científica dirigida por Ryan Coogler foi a primeira superprodução americana a ter, em sua grande maioria, atrizes e atores negros.

${ }^{10}$ O filme dirigido por Jordan Peele trata sobre questões raciais e foi premiado com o Oscar de Melhor Roteiro Original em 2018.

${ }^{11}$ A mais nova minissérie de Ava DuVernay é baseada na história dos cinco adolescentes negros que foram condenados injustamente por um estupro ocorrido em 1989, no Central Park.

${ }_{12}$ O premiado filme foi coescrito e dirigido por Spike Lee. Baseado no livro autobiográfico Black Klansman, de Ron Stallworth, ele conta a história de um policial negro do Colorado que consegue se infiltrar na Ku Klux Klan local.

${ }_{13}$ O discurso integral legendado está disponível em: https://www.youtube.com/watch?v=nlOVquKPUMU. Acesso em: 10 set. 2018.

${ }^{14}$ Aqui me refiro especialmente ao clipe da música "Chained to the rhythm", disponível em: http://bit. ly/36PUIy9. Acesso em: 10 set. 2018.

15 Nesse momento, faço referência ao polêmico clipe da cantora para a música "Vai malandra", gravado em uma favela carioca. Disponível em: http://bit.ly/381eQOc. Recentemente, o clipe da música "Muito calor", da cantora em parceria com o cantor porto-riquenho Ozuna, rendeu críticas semelhantes. Disponível em: http://bit.ly/3a8fpYs. Acesso em: 10 set. 2018.
} 
todos concordam com as boas intenções das cantoras. No caso dos clipes da brasileira, são recorrentes as acusações de que ela estaria - sobretudo quando deu início à sua carreira internacional - usando as imagens já fetichizadas da população negra e favelada do país com o intuito de se promover. Reafirmar a ideia do Brasil como lugar de costumes e paisagens exóticas pode ser interessante porque o "diferente" pode ser lucrativo. $\mathrm{E}$ as mesmas pessoas que pagam caros passeios para "turistar" pelas favelas cariocas em carros de safari, conseguem, com um click, essa amostra grátis oferecida por Anitta.

As críticas de que a cantora estaria, com isso, realizando uma apropriação cultural se tornaram ainda mais incisivas pois, por ter mudado drasticamente de visual desde que começou a fazer sucesso, Anitta é frequentemente acusada de embranquecimento - uma clara tática de aceitação e passabilidade em ambientes racistas. Nesse sentido, a questão que fica é: valorizar a cultura negra e periférica quando lhe é conveniente basta?

Em um caminho diferente, mas com um propósito semelhante, está o clipe da música "Me solta", do também carioca Nego do Borel ${ }^{16}$. Nele, o cantor aparece beijando um homem, mesmo não sendo gay e já tendo feito declarações homofóbicas. Portanto o que fica claro é que falar sobre questões de minorias para determinado público está “em alta”, mas não as minorias propriamente ditas, que seguem marginalizadas e tendo suas lutas silenciadas. Nesse sentido, há uma incorporação do discurso pela indústria do entretenimento porque ele se tornou lucrativo, e não por haver interesse real em lutar por essas causas. É evidente que esse movimento cumpre uma função social na medida em que ajuda a reordenar o preconceito, colocando-o em evidência e contribuindo para uma nova tomada de consciência social. Não estou aqui, portanto, recusando a importância desse engajamento, apenas chamo atenção para o fato de que é preciso olhar para além desses "discursos bem-intencionados" para conseguir localizá-los de maneira mais profunda. Também não digo que o clipe de Gambino necessariamente ocupe esse lugar. Entretanto trago essa breve reflexão por considerar que, além de ser uma questão fundamental de ser discutida, a excelente recepção que "This is America” e vários outros trabalhos

\footnotetext{
${ }^{16}$ O clipe da música está disponível em: http://bit.ly/3ab9gLd. Acesso em: 10 set. 2018.
} 
que vão em direções semelhantes tiveram, sem dúvida, está relacionada com o momento que a indústria do entretenimento está vivendo ${ }^{17}$.

Além do que foi dito, creio que o vídeo teve larga projeção, pois conseguiu trazer uma discussão que, embora trate mais diretamente da tensão racial nos Estados Unidos, fala sobre uma realidade que toca muitas outras, ultrapassando o debate em questão. Esse foi o meu caso. Não há dúvida de que o registro audiovisual fala sobre uma realidade cruel vivenciada por milhares de negros norte-americanos, mas, para mim, ele fala sobre uma política de extermínio de jovens negros com a qual eu fui obrigada a conviver quando vim morar no Rio de Janeiro e passei a trabalhar em favelas. Foi por isso que essa obra, em especial, me tocou e foi por isso que decidi pensar mais profundamente sobre ela.

Algumas interpretações apontaram na direção de entender o próprio Gambino, em seu clipe, como uma representação da América, dos Estados Unidos. Apesar disso, ele me remeteu à forma como o Estado governa a vida e a morte do povo preto nas favelas cariocas. Explicarei melhor essa associação no tópico seguinte.

\section{REFLEXÕES SOBRE NECROPOLÍTICA E SUAS CONSEQUENCIAS NO RIO DE JANEIRO}

O racismo de Estado, ao qual se referia Foucault (2008), é um elemento crucial para entender a economia da vida e da morte. Ao estabelecer uma hierarquia de pessoas, ele se transforma na condição para que se estabeleçam as possibilidades diferenciais de gestão de corpos e territórios. A sociedade, sob essa ótica, é compreendida como um campo de forças que permite gerir essas diferenças para proteger certas vidas e eliminar outras, aquelas que representam um risco dentro do grupo social. São tecnologias que atravessam o corpo,

\footnotetext{
17 Também é preciso ponderar que, de maneira geral, conteúdos que tratam da violência tendem a se tornar fonte imediata de interesse por parte de uma população que mercantiliza o horror. Infelizmente, não será possível refletir sobre isso com maior profundidade neste momento.
} 
que desponta como local de exercício de poder, definindo, assim, quem vive e quem morre.

Agamben (2007) reformula a teoria foucaultiana sugerindo que a biopolítica moderna converteu-se em tanatopolítica, em que haveria a produção política de certas mortes para garantir certas vidas. Ele recupera uma discussão clássica sobre a vida, entendida como vida natural (zoé) e vida política (bio) para refletir sobre a figura do homo sacer, uma vida nua. Segundo o autor, há uma produção cotidiana, política e administrativa, encarnada em um conjunto de táticas e burocracias, mobilizadas para a instalação desse corpo passível de sofrer violência, dessa vida sem valor.

Justamente porque privados de quase todos os direitos e expectativas que costumamos atribuir à existência humana e, todavia, biologicamente ainda vivos, eles vinham a situar-se em uma zona-limite entre a vida e a morte, entre o interno e o externo, na qual não eram mais que vida nua (AGAMBEN, 2007, p. 166).

O estudo, que inicialmente refletia sobre os campos de concentração nazistas, se expande para ver esses campos como uma "localização deslocante", onde o Estado de exceção não diz respeito a uma situação externa e provisória de perigo, mas se confunde com o próprio ordenamento.

Nessas "ásperas zonas de indiferença" habita a vida matável, social e politicamente produzida para não ser mais vida, mas "morte em movimento". Incluído pela exclusão, esse corpo humano é desligado de seu estatuto político normal e pode ser morto sem que se cometa homicídio, posto que apenas é entregue ao que já pertence.

Para o autor, na biopolítica moderna, a soberania se reconfigura, torna-se difusa, operando por meio dos funcionários, que têm a prerrogativa de decidir sobre o valor e o desvalor da vida. Desse modo, às vidas que nascem negadas em nome das vidas que contam, só cabe a fuga perpétua diante das várias camadas de desfazimento que se lhe impõe.

O Estado de exceção, portanto, opera no interior do Estado de Direito e é o modo pelo qual esse Estado se mantém. O campo é o corte móvel e 
permanente onde é possível produzir a morte. O "paradigma político oculto da modernidade" que é colocado fora do ordenamento jurídico normal, mas que lhe é constituinte.

Em direção semelhante, Mbembe (2016) acredita que a soberania seja fundada sob o mito de que a existência do outro representa uma "ameaça mortal" ou um "perigo absoluto" para si, de modo que a eliminação desse inimigo ficcional reforçaria o potencial para sua própria vida e segurança. Por essa razão é que a soberania tem como atributos fundamentais o poder e a capacidade de definir quem é "descartável" e quem não é e, assim, decidir quem pode viver e quem deve morrer. Ocorre que, para o autor, há formas novas e únicas de existência social atualmente, nas quais as pessoas são submetidas a condições que lhes conferem o status de "mortos-vivos". Diante desses "mundos de morte" e das formas contemporâneas de subjugação da vida ao poder da morte, não seria então suficiente pensar em termos de biopoder, mas de necropoder. Nesse contexto de terror, a soberania se pulveriza e passam a ser acionadas diferentes tecnologias da destruição

Um mosaico de direitos de governar incompletos e sobrepostos, disfarçados e emaranhados, nos quais sobejam diferentes instâncias jurídicas de facto geograficamente entrelaçadas, e nas quais abundam fidelidades plurais, suseranias assimétricas e enclaves (MBEMBE, 2016, p. 139).

Após essa pequena digressão, creio que seja possível refletir sobre o clipe em análise, levando também em consideração a minha vivência como produtora cultural, atividade que desempenho há mais de três anos em favelas e periferias cariocas.

Há diferentes modos de regulação social e são variadas as formas de resistir a eles. Olhando para o clipe de Gambino, foi possível refletir sobre a relação do Estado com a população negra e favelada no Brasil. Nessas economias que produzem corporalidades e territórios desiguais, o clipe emerge como matéria prima para compreender essa engrenagem de gestão governamental das mortes dessa população. 
O racismo é um processo histórico vivido de diferentes formas a depender da realidade em questão. Por essa razão, falar sobre a questão racial nos Estados Unidos é infinitamente diferente de pensá-la no Brasil. O mito da democracia racial ao qual se referia Freyre $(2003)^{18}$ permitiu a instalação de um racismo velado no país que até hoje se perpetua e é motivo de questionamento. A ideia da miscigenação findou por obscurecer formas de opressão racial e, como revelado por Fernandes (1965), se tornou a justificativa estatal para se esquivar de promover um engajamento capaz de combater a discriminação racial. Isso, por si só, se choca brutalmente com a realidade norte-americana, em que o racismo é escancarado, dando-lhe diferentes conotações. Faço esse pequeno paralelo para demonstrar que, ao usar o clipe de Glover para pensar a situação brasileira e, mais especificamente, a carioca, não pretendo anular essas disparidades para aproximar tais realidades, mas tão somente para destacar o poder que a arte tem de acessar regiões do outro que ultrapassam a mensagem daquele que a concebeu.

Uma das formas mais evidentes de materializar a magnitude da desigualdade racial no Brasil é a forte concentração de homicídios contra a população negra. Em 2016, de acordo com o Atlas da violência 2018, a taxa de homicídios de negros foi de $40,2 \%$ contra $16,0 \%$ de não negros (INSTITUTO DE PESQUISA ECONÔMICA APLICADA). No período de uma década, entre 2006 e 2016, a taxa de homicídios de negros cresceu 23,1\% enquanto a taxa entre os não negros teve redução de $6,8 \%$. Nesse mesmo período, a taxa de homicídios de mulheres negras foi $71 \%$ superior à de mulheres não negras. A situação se agrava ainda mais quando são inseridos critérios etários, de modo que o risco de um jovem negro ser vítima de homicídio no Brasil é 2,7 vezes maior que o de um jovem branco. São eles, também, as principais vítimas de ações letais das polícias ${ }^{19} \mathrm{e}$ o perfil predominante da população prisional brasileira.

Assim, olhando para aquele clipe americano tão cheio de subtextos e interpretações possíveis, o que é possível dizer sobre a realidade carioca?

\footnotetext{
${ }_{18}$ Embora Freyre jamais tenha usado esse termo em Casa-Grande \& Senzala, obra lançada em 1933, o conceito foi apresentado inicialmente por meio dele e o autor passou a adotá-lo em publicações posteriores.

19 O Anuário Brasileiro de Segurança Pública 2017 identificou que 76,2\% das vítimas de atuação da polícia são negras (FÓRUM BASILEIRO DE SEGURANÇA PÚBLICA, 2017).
} 
Vendo aquelas mortes, o que se pode dizer sobre certas vidas? Em que elas se distinguem da vida nua da qual falava Agamben (2007)? Quais são as vidas que contam e as vidas matáveis? O que têm os policiais militares do Rio de Janeiro em comum com os funcionários de Guantánamo aos quais se referia Butler (2006)? Esses que reanimam outro formato de soberania, pois têm o poder de decidir sobre a vida e a morte. Poderíamos, nesse contexto, falar em um Estado de exceção que se integra ao ordenamento jurídico? O que são os carros de polícia vazios no clipe? Creio que, para entender essas mortes, seja preciso conceber que, em algum lugar nessa teia de governamentalidades, certas vidas deixaram de ser ontologicamente concebidas como vidas humanas.

Sujeitas a governamentalidades desiguais e expostas de maneira diferenciada à morte, notamos que essas gradações de humanidade se precipitam quando olhamos para certas "zonas nubladas" de terror iminente. Nesses lugares constroem-se e corroem-se as vidas negadas que já nascem para ser eliminadas. Nesse sufoco - ora microscópico, ora escancarado - os que sobrevivem também morrem pouco a pouco na guerra do cotidiano marginal. Sorrateiramente minados, progressivamente cerceados até da construção de um horizonte de possibilidades, esses sujeitos têm suas vidas continuamente subtraídas, capturadas (GONZALO, 2016).

Como afirma Farias (2014), essas pessoas sabem exatamente as condenações que recaem sobre elas, mas as enfrentam cotidianamente. Diante dessas tecnologias de governo que produzem em suas miudezas a destruição, eles tateiam saídas, brechas, enquanto desenvolvem essa "arte do contornamento".

Para gerar tensionamentos e fissuras nessa engrenagem, para traçar novos arranjos e cartografias para suas vidas e mortes, esses sujeitos se reinventam e, em diferentes escalas, constroem novos repertórios de ação que escapem a essas capturas. Mesmo emaranhados nessas tramas de destruição, eles encontram condições de se autoproduzir, criam caminhos que corroem e fragilizam esses governos da morte ao qual estão sujeitos. Glover corre. Desesperado e perseguido, ele corre e não se deixa alcançar. Olho para essa fuga e vejo a captura à qual se refere Gonzalo (2016), mas vejo também muita luta e resistência. Corre Gambino, correm meus interlocutores, exaustos, mas incansáveis à captura do dia a dia. 


\section{A SUBJETIVIDADE DA ARTE E ALGUMAS CONSIDERAÇÕES}

O caminho proposto parte da compreensão de que, quando se trata de expressar um sentimento - no caso, do que é viver como um negro em uma sociedade racista que tem a morte como política de Estado -, o realismo torna-se insuficiente e a mensagem escapa à literalidade da fala. É justamente aí que reside a potência do clipe de Glover. "As imagens tomam parte do que os pobres mortais inventam para registrar seus tremores (de desejo e de temor) e suas próprias consumações" (DIDI-HUBERMAN, 2012, p. 210).

Portanto, sendo a imagem um "corte praticado no mundo dos aspectos visíveis. É uma impressão, um rastro, um traço visual do tempo que quis tocar, mas também de outros tempos suplementares - fatalmente anacrônicos, heterogêneos entre eles - que não pode, como arte da memória, aglutinar” (DIDI-HUBERMAN, 2012, p. 216), meu esforço foi o de olhar para essa brecha da imagem que "sobreviveu a uma experiência", mas que gerou uma interpretação imaginativa, que não é imediata nem fácil de entender, que não está "no presente", mas que o incendeia.

Esse caminho de produzir o discurso que foge às narrativas tradicionais se potencializa porque comunica por meio da performance, das disposições corporais mimetizadas, das narrativas congeladas que recuperam o que não pode ser descrito. Através desse dispositivo, o autor dá conta de alcançar dimensões do indizível que tocam e comunicam pela emoção. A partir dessa experiência sensível, se produz a afetação que faz que sejam ultrapassadas quaisquer prescrições objetivas. Abrindo mão dessa ideia de significado total, é possível enxergar para além dele.

Por meio de símbolos e alegorias corporais, ele é capaz de gerar associações mentais não tão aparentes, mas que tocam profundamente sobretudo pelo excesso, pelo escancarar, pela devolução da "violência" sofrida. Por essa razão, a letra da música, nesse caso, não basta. Sua voz só se completa com a imagem, e a mensagem só se conclui com o outro, que a sente. 
Entendendo que, como coloca Das (1999), muitas vezes não há nexo possível para comunicar certos sentimentos e que, por isso, a fala desponta como uma limitadora da mensagem, encontramos aqui a potência da imagem, que emerge como ampliadora das possibilidades ao transmitir realidades não palpáveis que se costuram concretamente na vida de uns, mas se expandem para além dessa materialidade. Aí, quando não há um eixo possível para comunicar a integralidade de uma dor, quando a narrativa realista é limitada, a imagem se constrói como caminho, trazendo um corpo político que comunica e acionamentos estéticos que são, na verdade, elaborações discursivas essenciais à composição da mensagem.

Por meio do clipe de Glover é possível entender como a imagem é, ela própria, uma forma de conhecimento que dá a ver algo que não seria possível comunicar por outro meio. Mais do que isso, ele permite refletir sobre como a obra audiovisual não é só um produto, posto que também produz algo. Tornase um acontecimento. A crítica pela imagem, nesse sentido, é capaz de alcançar um patamar que se revela como um terreno fértil para produzir novas formas de atingir o outro e propor uma experiência transformadora.

Mais do que significado, essa relação áudio/visual se transforma em sensação. Portanto há um simbólico que atua, mas que é ultrapassado. Por meio da experiência sensorial, somos levados a um outro tempo e local, onde a memória atua como ponto-chave e os deslocamentos de sentido se tornam inevitáveis.

\section{REFERÊNCIAS BIBLIOGRÁFICAS}

1. AGAMBEN, Giorgio. Homo sacer: o poder soberano e a vida nua I. Belo Horizonte: Editora UFMG, 2007.

2. ALONSO, Guillermo. Por que o violento "This is America" é o videoclipe do ano (preste atenção no que acontece ao fundo). El País, Madri, 2018. Disponível em: http://bit.ly/35JjHSq. Acesso em: 6 ago. 2018.

3. BUTLER, Judith. Vida precaria: el poder del duelo y la violencia. Buenos Aires: Paidós, 2006. 
4. DAS, Veena. Fronteiras, violência e o trabalho do tempo: alguns temas wittgensteinianos. Revista Brasileira de Ciências Sociais, São Paulo, v. 14, n. 40, p. 31-42, 1999.

5. DAVIS, Angela. Mulheres, raça e classe. São Paulo: Boitempo, 2016.

6. DIDI-HUBERMAN, Georges. Pós: Revista do Programa De Pós-Graduação em Artes da Escola de Belas Artes da UFMG, Belo Horizonte, v. 2, n. 4, p. 204-219, 2012.

7. FARIAS, Juliana. Governo das mortes: uma etnografia da gestão de populações de favelas no Rio de Janeiro. 2014. Tese (Doutorado em Sociologia) - Universidade Federal do Rio de Janeiro, 2014.

8. FERNANDES, Florestan. A integração do negro na sociedade de classes. São Paulo: Dominus Editora, 1965. 2 v.

9. FÓRUM BRASILEIRO DE SEGURANÇA PÚBLICA. Anuário Brasileiro de Segurança Pública 2017. São Paulo, 2017. Disponível em: http://bit.ly/39ZWT4g. Acesso em: 6 ago. 2018.

10. FOUCAULT, Michel. Segurança, território, população. São Paulo: Martins Fontes, 2008.

11. FREYRE, Gilberto. Casa-Grande \& senzala: formação da família brasileira sob o regime da economia patriarcal. 48. ed. São Paulo: Global, 2003.

12. GONZALO, Ignacio Mendiola. El dispositivo de la captura: espacios y cuerpos bajo el signo de la excepcionalidade. Athenea Digital, Bellaterra, v. 16, n. 1, p. 83-111, 2016.

13. INSTITUTO BRASILEIRO DE GEOGRAFIA E ESTATÍSTICA. Censo 2010. Rio de Janeiro, 2010. Disponível em: http://bit.ly/36IGY8A. Acesso em: 6 ago. 2018.

14. INSTITUTO DE PESQUISA ECONÔMICA APLICADA. Atlas da violência 2018. Rio de Janeiro, 2018. Disponível em: http://bit.ly/2R1kUPQ. Acesso em: 6 ago. 2018.

15. JUNIOR, Jacido. Childish Gambino: os significados escondidos em "This is America”. Omelete, São Paulo, 2018. Disponível em: http://bit.ly/2tQvRMo. Acesso em: 6 ago. 2018.

16. KATZ, Jack. Seductions of crime: moral and sensual attractions in doing evil. New York: Basic Books, 1988.

17. MARTÍNEZ, Héctor Llanos. As referências de "This is America", o canto antirracista de Childish Gambino. El País, Madrid, 2018. Disponível em: http:// bit.ly/2T97zaV. Acesso em: 6 ago. 2018. 
18. MBEMBE, Achille. Necropolítica. Arte \& Ensaios, Rio de Janeiro, n. 32, p. 123-151, dez. 2016.

19. TERTO, Amauri. O incômodo clipe de "This is America", de Childish Gambino (o Donald Glover). HuffPost, São Paulo, 2018. Disponível em: http://bit.ly/2NeEy9P. Acesso em: 6 ago. 2018. 